\title{
Mechanism of the Original Ecology Gravity Irrigation in the Ziquejie Terrace
}

\author{
Li Guiyuan, Liu Siyan, Luo Lishun, Hu Chunyan \\ Hunan Water Resources and Hydropower Research Institute, Changsha, China
}

\section{Email address:}

LGY7698@163.com (Li Guiyuan)

\section{To cite this article:}

Li Guiyuan, Liu Siyan, Luo Lishun, Hu Chunyan. Mechanism of the Original Ecology Gravity Irrigation in the Ziquejie Terrace. American Journal of Water Science and Engineering. Vol. 4, No. 2, 2018, pp. 40-49. doi: 10.11648/j.ajwse.20180402.15

Received: July 12, 2018; Accepted: July 31, 2018; Published: September 3, 2018

\begin{abstract}
The Ziquejie Terrace is one of the three famous ancient terraces in China. Rice has been planted in large area with mountains standing and a lot of steep hills. Whatever the weather is drought or rainstorm, the rice can always have a good harvest without water storage facilities. To reveal the mechanism of the original ecology gravity irrigation, several investigations had been developed such as observation of hydrology and meteorology, hydro-geological exploration and dynamic monitoring of groundwater level. According to the results of the experimental observations, this article proposed a suit of perfect theories and methods, such as the nonlinear autonomic regulation theory and "the ground water reservoir on the same slope position" theory in ancient terrace area. Further more, the calculation model of the original ecology gravity irrigation water cycle balance was established and a set of theories and methods of the water cycle balance calculation were formed on the basis of prior theories. Using this model, the process of irrigation water supply and demand balance, as well as the irrigation assurance, was simulated at rice growth stages in the original gravity irrigation area and its surrounding artificial irrigation area. The results showed that there is a highly consistency between the simulation results and the measured results, and it revealed the mechanism of ancient ecological gravity irrigation profoundly in terraces area. The result of study has important directive significance to the exploitation and protection of the terrace in China and has important reference value to the exploitation of the slope farmland.
\end{abstract}

Keywords: Ancient Terrace, Gravity Irrigation, Autonomic Regulation and Storage, Mechanism

\section{Introduction}

The Purple Terraces ancient terraced rice fields are located in the Fengjiashan system of Xinhua County, Hunan Province. The system is based on the pinnacle of 1585.2 meters above sea level in the territory and is fan-shaped in the northeast direction. The range is about 93 square kilometers. Rice is planted all year round and the planting area is about 60,000 $\mathrm{mu}$. The terraced fields are built on a mountainous basis. From 450 meters to 950 meters above sea level, there are more than 500 levels and more than ten thousand hills. On the slopes, the terraces are stacked one on top of the other and the overall layout is magnificent. It is like the Heavenly Jade Pool, one of the three most famous ancient terraces in China.

People were amazed by the magical landscape of the terraces of the purple and sinuous fields, and water conservators are paying more attention to the intrinsic mechanism of the magical phenomena of the original ecological gravity irrigation system in the terraces of the crimson and pygmy communities. The hills are steep and steep and grow large areas of rice, and they will last for thousands of years. There is no irrigation water source facility such as water storage and water storage in the mountains. However, despite the fact that the weather and rainstorms can make people prosperous and flourish, they are known as "there is a great deal of drought in the world". Water is the foundation of the ecology that supports the ancient terraces and the life. Studying the sources, storage forms, supply methods, and migration and transformation laws of irrigation sources for the terrace irrigation system in the cichlid and arid ecosystem, and revealing the intrinsic mechanism of this magic phenomenon is not only necessary to better develop, utilize and effectively protect the natural heritage of the ancient terraces. The theoretical basis is also of important reference value for the protection and development of other ancient terraced fields in China. 


\section{Experimental Observation System}

In order to study all aspects of the original geopotential irrigation mechanism of ancient terraced fields, two rainfall-runoff observation stations, two meteorological observation stations, three groundwater level observation stations, and nine hydrogeological drill holes were deployed in the study area in 2011. Continuous observations of regional hydrology, meteorology, and groundwater levels were conducted, and two consecutive years of experimental observation data were obtained from 2012 to 2013. Geological drilling and related water level geological experiments were completed.

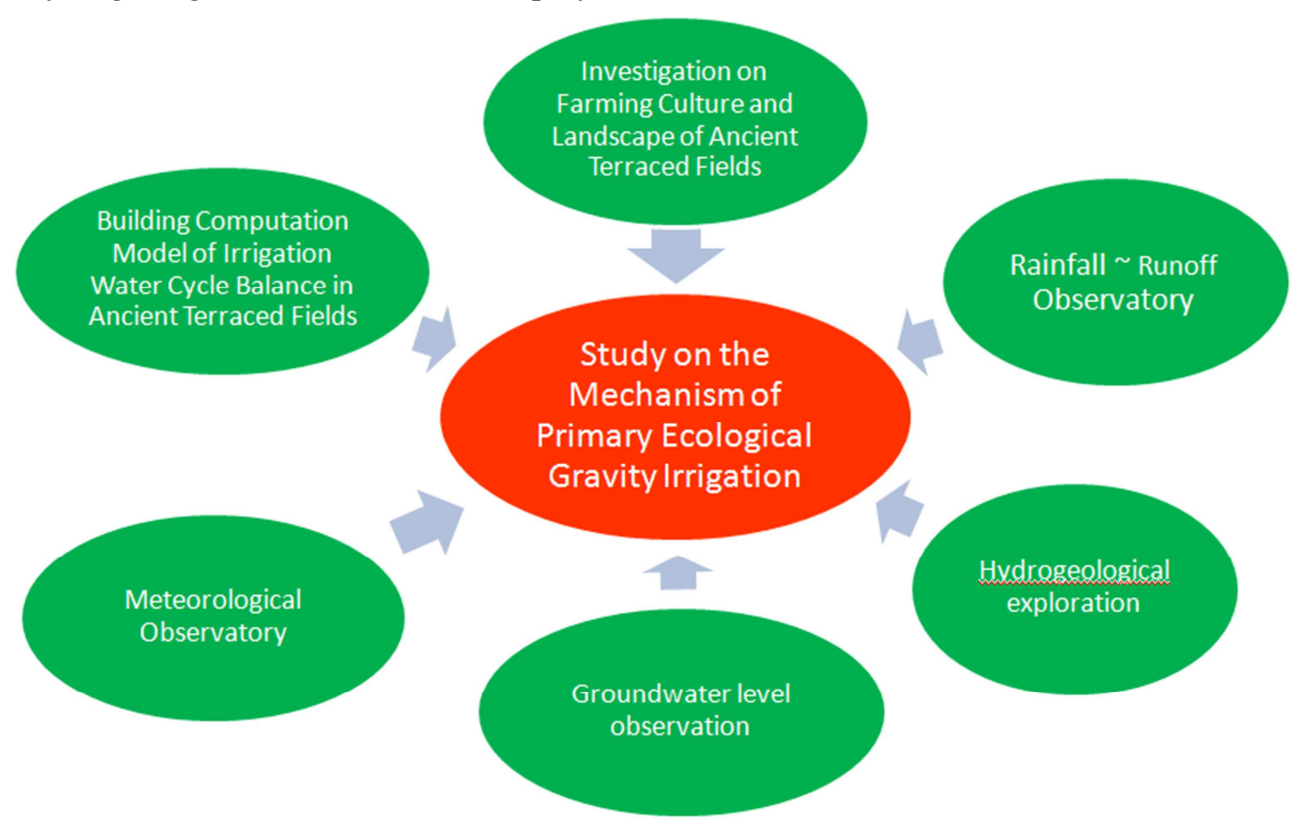

Figure 1. Design of an experimental observation system for gravity flow irrigation mechanism in ancient terrace.

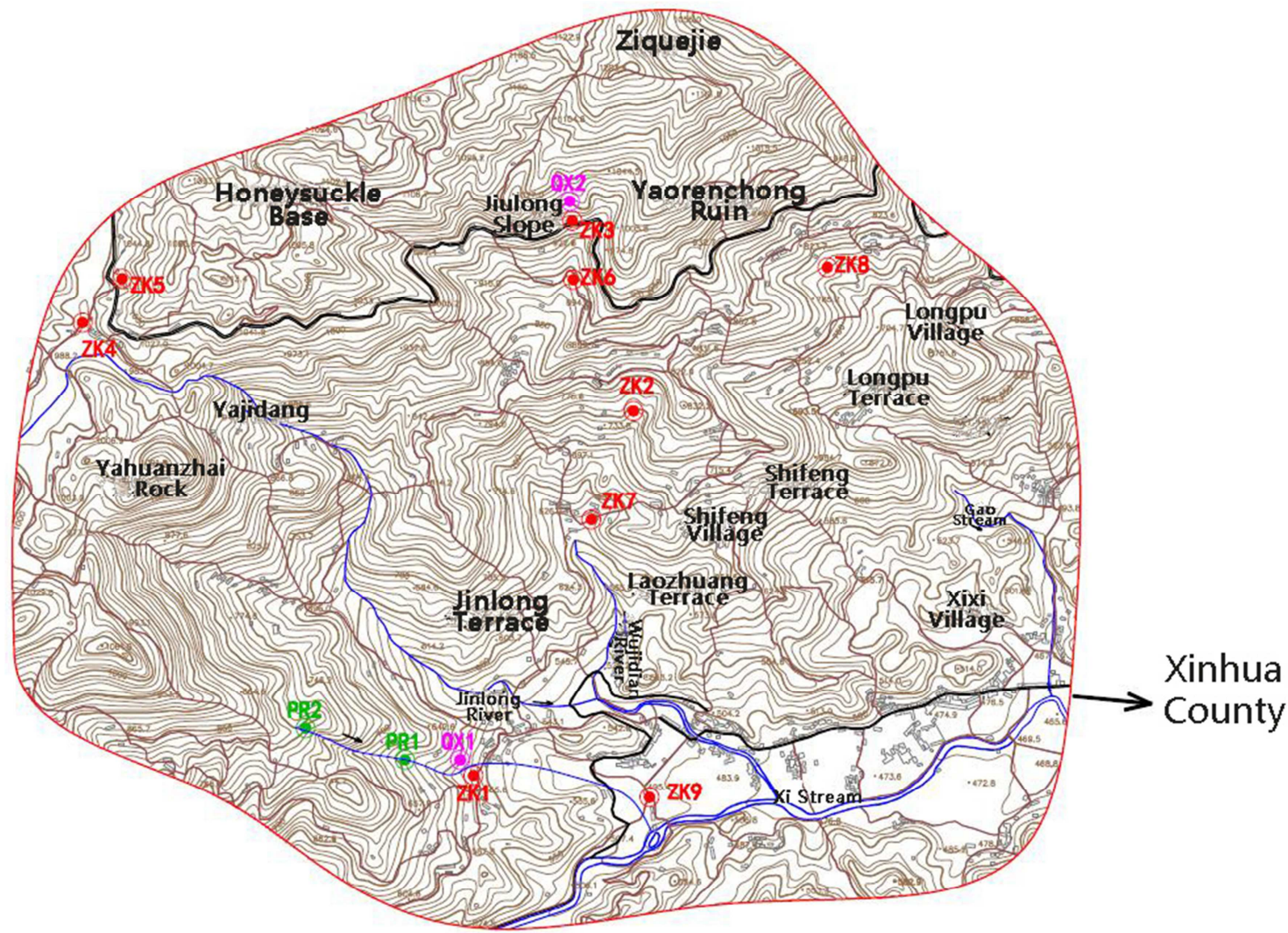

ZK Hydrogeological drilling $\bigcirc$ QX Weather station

(-) PR Rainfall-runoff observation station

Figure 2. Experimental station layout. 


\subsection{Rainfall to Runoff Observatory}

In order to explore the characteristics of rainfall-runoff in the ancient terraced area, a small watershed with a closed boundary is selected in the ancient terraced region, and a control section is selected at the upstream and downstream outlets, and a rainfall-runoff observation station is established to perform rainfall-runoff observation (see Figure 3 ). The control area of station A is basically the original ecological natural vegetation coverage area, and the controlled rain collection area is $5.48 \mathrm{hm} 2$. The interval between station A and station $\mathrm{B}$ is basically a terraced area with a rain collection area of $6.17 \mathrm{hm} 2$. Daily rain-runoff observation data from 2011 to 2013 have been obtained.

\subsection{Meteorological Observatory}

Climate factors are important ecological environmental factors that directly affect the characteristics of ecological vegetation and crop water requirements. The weather observations mainly include wind speed, rainfall, atmospheric pressure, temperature, radiation, sunshine hours, humidity, and evaporation.

Two meteorological observation stations were set up at the foot of the mountain (A station, 650m elevation) and mountain peak (station B, 1000m elevation). Station A observed the climate of the terraced area, and Station B observed the climate of the peak forest vegetation area. At the same time, the data of Xinhua County Meteorological Station was quoted to analyze the differences in climate characteristics between the ancient terraced region and the surrounding submount, and also provided basic data for the long series of calculation and analysis of the ancient cropland crop water requirement law and the ancient terraced natural irrigation guarantee rate. We have obtained continuous observation data from stations A and B from 2012 to 2013 and continuous weather data from 1971 to 2013 in Xinhua County.

\subsection{Hydrogeological Exploration}

In order to identify regional hydrogeological structures, study groundwater reserves, recharge and drainage regulations, nine geological exploration drill holes were drilled with a total depth of 158 meters. Combined with drilling, three drills were selected along the ridgeline at mountain peaks, mountainsides, and foothills. Holes carry out pumping and water injection tests to obtain the necessary hydrogeological parameters.

\subsection{Groundwater level Observation}

In combination with geological drilling, three groundwater level observation wells were placed on the mountain peaks, mountainsides, and foothills to carry out groundwater level observations. Has obtained continuous observation data for two years from 2012 to 2013.

\section{Analysis of Experimental Observations}

\subsection{Rainfall - Runoff and Infiltration Recharging Characteristics}

The digital filter was used to divide the observed annual runoff into surface runoff and baseflow process lines. Digital filtering is a method used in digital signal analysis to separate high-frequency signals from low-frequency signals. In recent years, the digital filtering method has been widely used in base stream segmentation. The surface runoff representing rapid response to rainfall runoff is similar to the high frequency part of the digital signal. The base flow representing the slow response result is similar to the low frequency in the digital signal. Partially, therefore, digital filtering can be applied to baseflow segmentation of runoff sequences.

The filter equation applied to the basic flow segmentation is:

$$
\begin{gathered}
\mathrm{q}_{\mathrm{t}}=\beta \mathrm{q}_{\mathrm{t}-1}+[(1+\beta) / 2]\left(\mathrm{Q}_{\mathrm{t}}-\mathrm{Q}_{\mathrm{t}-1}\right) \\
\mathrm{b}_{\mathrm{t}}=\mathrm{Q}_{\mathrm{t}}-\mathrm{q}_{\mathrm{t}}
\end{gathered}
$$

In the equation, qt is the direct surface runoff that is filtered out at time $\mathrm{t} ; \beta$ is the filter parameter, which affects the attenuation of the base flow. In the calculation, $\beta$ is taken as 0.95; Qt is the actual measured total runoff at time $t$; bt is the base flow. In order to improve the calculation accuracy, it is necessary to carry out repeated filtering of the measured runoff sequence in forward and reverse order.

Figure 3 is the segmented runoff process line and baseflow process line for station A in 2012. The damping and hysteresis effects of the basin's underlying surface on the convergence of rainfall to the drainage basin determine that the process line of underground runoff should be a smooth curve. It can be seen from the figure that the basic flow process line obtained by the digital filtering method is smooth and consistent with the baseline. Flow process characteristics.

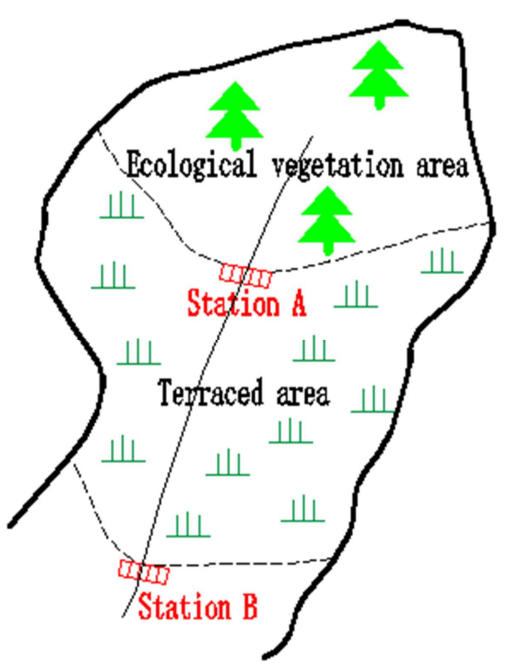

Figure 3. Rainfall runoff observation basin 


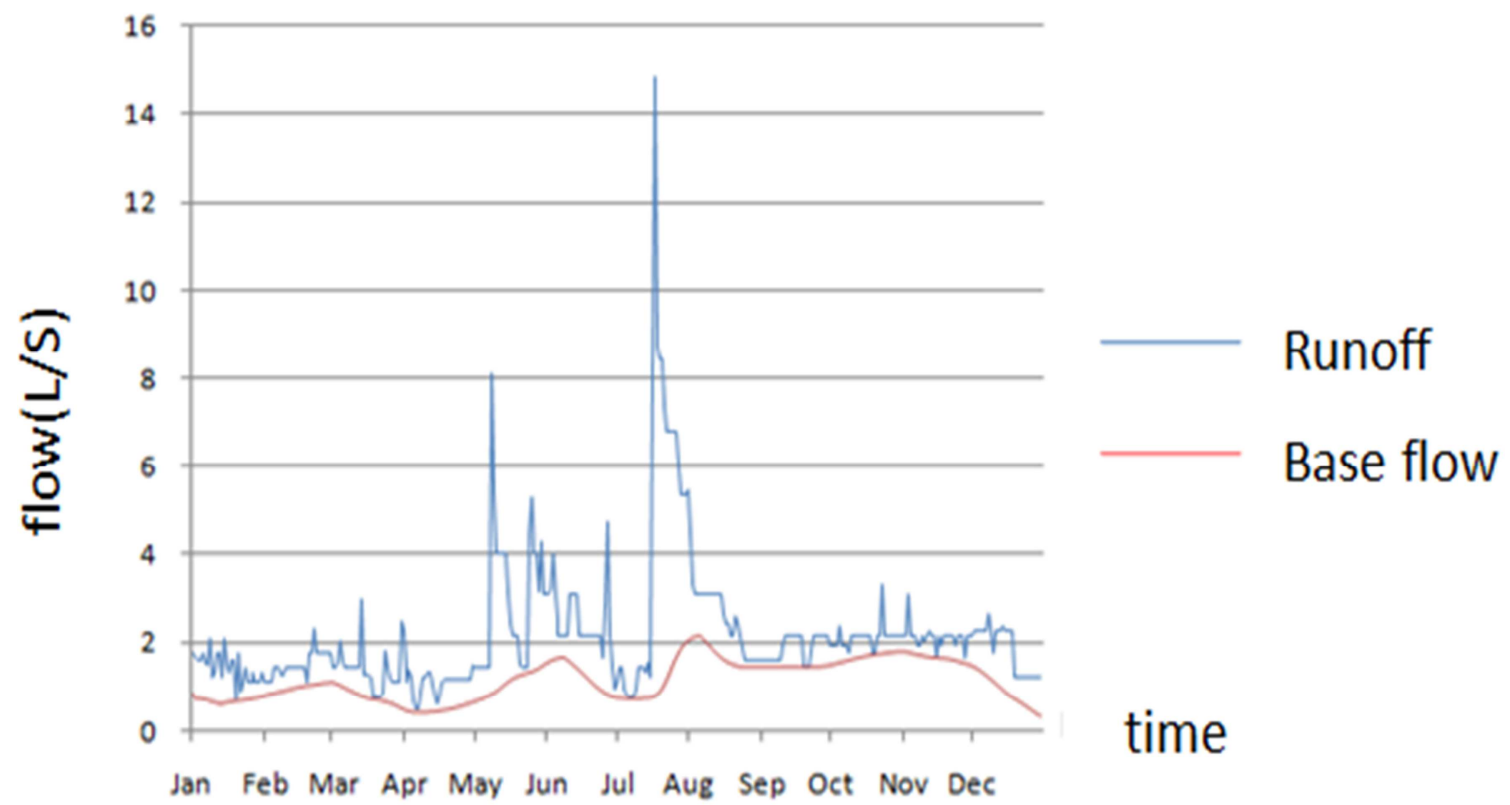

Figure 4. A Station Runoff Process Line Segmentation in 2012.

According to the statistics of runoff separation lines of stations A and B, the runoff characteristics of different landform conditions are shown in the following table:

Table 1. Rainfall-runoff characteristics indicators in ecological vegetation area and terrace area.

\begin{tabular}{|c|c|c|c|c|c|c|c|c|}
\hline $\begin{array}{l}\text { Landform } \\
\text { condition }\end{array}$ & $\begin{array}{l}\text { Control area } \\
\left(\mathrm{hm}^{2}\right)\end{array}$ & $\begin{array}{l}\text { Total rainfall } \\
(\mathbf{m m})\end{array}$ & $\begin{array}{l}\text { Total runoff } \\
\left(10^{4} \mathrm{~m}^{3}\right)\end{array}$ & $\begin{array}{l}\text { Runoff } \\
\text { coefficient }\end{array}$ & $\begin{array}{l}\text { Runoff modulus } \\
\left(10^{4} \mathrm{~m}^{3} / \mathrm{hm}^{2}\right)\end{array}$ & $\begin{array}{l}\text { Total base } \\
\text { flow }\left(10^{4} \mathrm{~m}^{3}\right)\end{array}$ & $\begin{array}{l}\text { Base flow modulus } \\
\left(10^{4} \mathrm{~m}^{3} / \mathrm{hm}^{2}\right)\end{array}$ & $\begin{array}{l}\text { Base flow } \\
\text { coefficient }\end{array}$ \\
\hline $\begin{array}{l}\text { Ecological } \\
\text { vegetation area }\end{array}$ & 5.48 & 1814.5 & 6.75 & 0.68 & 1.23 & 3.18 & 0.42 & 0.32 \\
\hline Terraced area & 6.17 & 1814.5 & 6.52 & 0.58 & 1.06 & 2.91 & 0.23 & 0.26 \\
\hline
\end{tabular}

The above results indicate that: 1) In the climatic region, the proportion of the base flow in the total runoff is as high as $42 \%$ (terracing area) to $47 \%$ (ecological vegetation area), far exceeding the general area experience value of Hunan Province $(20 \% \sim 30 \%)$, indicating that the area has strong rainfall infiltration recharge capacity and strong water conservation capacity; 2: Runoff modulus, base flow modulus and base flow coefficient of the ecological vegetation area is much larger than the terrace area, indicating that the mountain top forest cover The area has more powerful water storage and water retention capabilities.

\subsection{Regional Climate Characteristics and Ecological Water Demand}

Climate observations indicate that the ancient terraced area of the Ziyi Community has a unique and favorable community climate. Compared with hilly areas around the mountains, it has long hours of sunshine, low wind speed, high humidity, and low ecological water demand. These characteristics are very conducive to the growth of rice and rice quality, but also conducive to water conservation. The ancient terraced area can make full use of this unique residential climate, planting high-quality red rice and black rice with higher added value.

\subsection{Hydrogeological Characteristics}

Geological drilling and water level geological tests revealed that the hydrogeological structure in the region is simple and can be divided into three layers. The cover layer is a strongly weathered granite sandy cohesive soil. The thickness is generally between 0 and 6.9 meters with an average thickness of 5 meters. The weathering layer is followed by a strong weathered granite layer with an average thickness of 8 meters. The next layer is fresh granite. The pumping test yields the hydrogeological characteristics such as the permeability coefficient and the water supply, as shown in the following table:

Table 2. Table of Results for Drilling and Water Injection Tests.

\begin{tabular}{lllll}
\hline Drilling number & Test section $(\mathbf{m})$ & Lithology & Test layer thickness $(\mathbf{m})$ & Permeability coefficient $(\mathbf{c m} / \mathbf{s})$ \\
\hline ZK1 & $2 \sim 5$ & Weathered granite & 3 & $8.9 \times 10^{-5}$ \\
ZK2 & $2.0 \sim 3.7$ & Sandy clay & 1.7 & $4.5 \times 10^{-4}$ \\
ZK3 & $1.5 \sim 6.9$ & Sandy clay & 4.4 & $5.7 \times 10^{-4}$ \\
\hline
\end{tabular}




\subsection{Groundwater Level Change Law and Isopoetic Groundwater Reservoir}

From geological borehole data and groundwater level observations, we found an interesting phenomenon: there is a high-water-contained groundwater storage belt in the Ziyishan Mountains, and its water surface is roughly parallel to the terrain slope. We named it "Positioned underground reservoir". The groundwater depth process line from June 2012 to July 2013, measured from three groundwater level observation wells of Shang (ZK3), Zhong (ZK2) and Xi (ZK1), and the contemporaneous rainfall process line are shown in Figure 5. The eigenvalue statistics are shown in Table 3:



Figure 5. Groundwater depth process line.

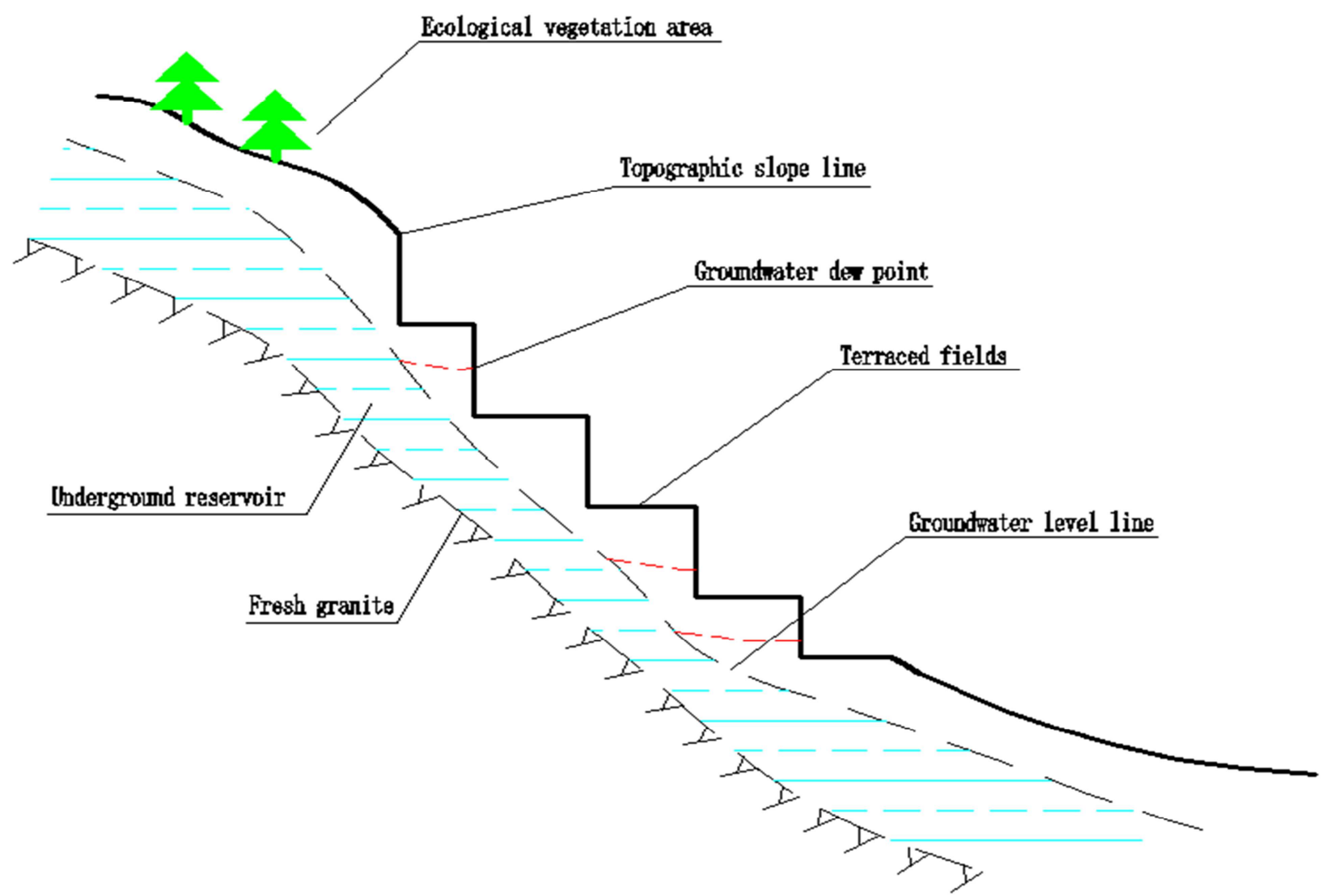

Figure 6. Schematic diagram of underground reservoirs at equal slope. 
Table 3. Table of Groundwater Depth Characteristics unit:m.

\begin{tabular}{|c|c|c|c|c|c|c|c|c|c|c|c|c|c|c|}
\hline & & July & August & September & October & November & December & January & February & March & April & May & June & July \\
\hline \multirow{3}{*}{ ZK1 } & lowest & 8.9 & 8.1 & 8.4 & 8.6 & 8.8 & 8.6 & 8.6 & 8.6 & 8.7 & 8.7 & 8.7 & 8.6 & 8.7 \\
\hline & highest & 7.8 & 7.2 & 8.3 & 8.5 & 8.6 & 8.5 & 8.1 & 8.6 & 8.4 & 8.2 & 8.4 & 8.4 & 8.4 \\
\hline & Falling depth & 1.1 & 0.9 & 0.1 & 0.1 & 0.2 & 0.1 & 0.5 & 0 & 0.3 & 0.5 & 0.3 & 0.2 & 0.3 \\
\hline \multirow[b]{2}{*}{ ZK2 } & lowest & 19.3 & 18.4 & 18.2 & 18.6 & 18.8 & 18.8 & 20.1 & 19 & 19.4 & 19.1 & 18.9 & 17.7 & 17.7 \\
\hline & highest & 15.6 & 15.3 & 17.8 & 18.1 & 18.4 & 18.4 & 18.3 & 18.8 & 19 & 18.9 & 17.5 & 17.4 & 16.5 \\
\hline \multirow{3}{*}{ ZK3 } & lowest & 19 & 17.4 & 18.1 & 18.3 & 18.5 & 17.9 & 18.7 & 18.9 & 19.9 & 18.1 & 17.4 & 16.9 & 17.7 \\
\hline & highest & 15.2 & 15.2 & 17.6 & 17.9 & 17.8 & 17.6 & 17.5 & 18.5 & 18.9 & 17.3 & 16.5 & 16.4 & 16.4 \\
\hline & Falling depth & 3.8 & 2.2 & 0.5 & 0.4 & 0.7 & 0.3 & 1.2 & 0.4 & 1 & 0.8 & 0.9 & 0.5 & 1.3 \\
\hline
\end{tabular}

The analysis of Figure 5 and Table 3 reveals that: 1 . The depth of the groundwater and the depth of collapse of the ancient mountain ranges from the peak (ZK3) to the mountainside (ZK2) are basically close at any time, and the process lines of the buried depths of the mountain and mountainside groundwater are basically coincident. It shows that there is a continuous and stable underground reservoir in the ancient terraced area all the year round, and the reservoir surface line is basically parallel to the contour of the hillside (downward slope). We call it the isograde groundwater reservoir, the principle of which is shown in Figure 6; 2. The maximum depth of fall in the underground water reservoir reaches 3.8 meters in the month, and the maximum depth of fall in the year reaches 4.7 meters, indicating that the groundwater reservoir has at least 4.0 meters of adjustment space; 3. The fluctuation trend of rainfall time and groundwater level greater than $50 \mathrm{~mm}$. There is a clear corresponding relationship, and the water level rises generally lags behind the rainfall for 5 to 8 days, indicating that the groundwater reservoir has a better function of storing and withering than the surface reservoir.

\section{Balanced Calculation Model of Original Ecological Gravity Irrigation Water Cycle in Ancient Terraced Area}

\subsection{Irrigation Water Supply and Demand Balance Principle}

The foregoing analysis shows that the groundwater pool at the position of the slope is the self-flow irrigation water source of ancient terraces. Rainfall infiltration is the recharge source of the reservoir, and the advantageous location above the terraces makes the groundwater reservoir flow slowly and continuously along the geological structure channel to the downstream terraces under the action of gravity, and becomes a terrace irrigation source. The principle of supply and demand balance of field irrigation water in terraced fields can be described as follows:

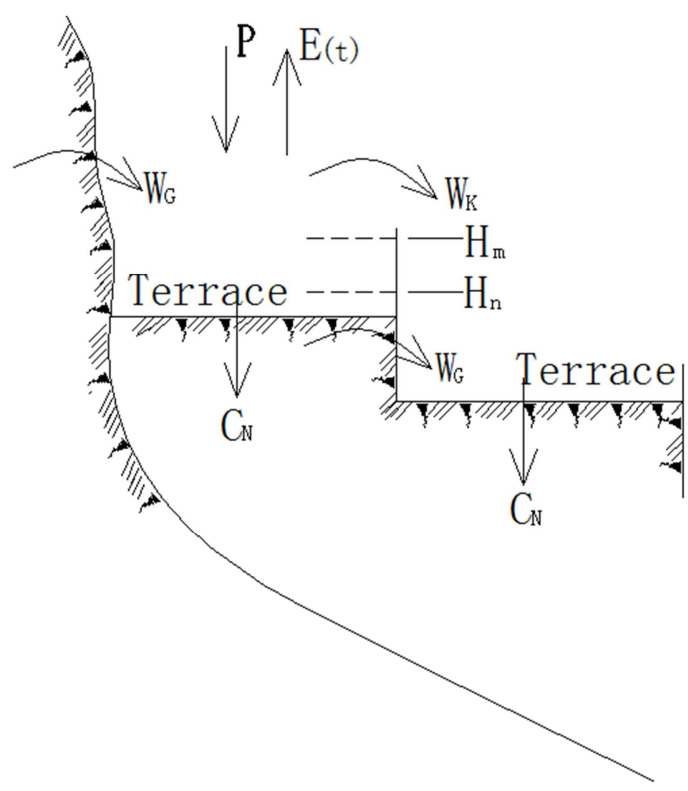

Figure 7. Schematic diagram of balance between supply and demand of irrigation water in ancient terraces.

The above figure shows that, except the rainfall, WG is the only source of irrigation water for terraces. According to the principle of water balance, the water depth $\mathrm{H}(\mathrm{t})$ at any time in the ancient terraces can be described by the following formula:

$$
\mathrm{H}(\mathrm{t})=\mathrm{H}(\mathrm{t}-1)+\mathrm{P}(\mathrm{t})+\mathrm{Rg}(\mathrm{t})-\mathrm{E}(\mathrm{t})-\mathrm{CN}
$$

In the formula:

$\mathrm{H}(\mathrm{t})$ _ At the end of the period $\mathrm{t}$, the depth of the terraced field $(\mathrm{mm})$

$\mathrm{H}(\mathrm{t}-1)$ - At the beginning of the time $\mathrm{t}$, the depth of the terraced fields $(\mathrm{mm})$

$\mathrm{P}(\mathrm{t})$ _ Effective use of rainfall during the period $\mathrm{t}(\mathrm{mm})$

$\mathrm{Rg}(\mathrm{t})$ _ Effective use of groundwater in terraced fields during the period $\mathrm{t}(\mathrm{mm})$

$\mathrm{E}(\mathrm{t})$ _ Field crop water consumption during the period $\mathrm{t}$ $(\mathrm{mm})$

$\mathrm{E}(\mathrm{t})=\mathrm{Kc} * \mathrm{ET} 0(\mathrm{t})$

$\mathrm{E}(\mathrm{t})$ Meteorological observation data and irrigation experiment data can be used to calculate the Penman formula.

$\mathrm{CN}-$ Terrace field leakage $(\mathrm{mm})$ According to the soil 
structure of terraces, take $\mathrm{CN}=2.5 \mathrm{~mm} / \mathrm{d}$

\subsection{Groundwater Reservoir Discharge (Outflow) Coupled with Irrigation and Drainage}

The outflow process of groundwater reservoir $\mathrm{WG}(\mathrm{t})$ is based on its own drainage rules. The part of water $\mathrm{Rg}(\mathrm{t})$ that can be used by terraces is not only related to $\mathrm{WG}(\mathrm{t})$, but also the depth of water in the terrace field at the beginning of the time period. t) related. Only when the field depth $\mathrm{H}(\mathrm{t})$ of the terrace is less than the upper limit $\operatorname{Hm}(\mathrm{t})$, the groundwater $\mathrm{WG}(\mathrm{t})$ entering the field is intercepted until the upper limit $\mathrm{Hm}(\mathrm{t})$ of water storage, and the groundwater intercepted in this part is $\operatorname{Rg}(\mathrm{t})$. ). When the water depth in the field exceeds $\mathrm{Hm}(\mathrm{t})$, the excess WG(t) naturally overflows and is channeled into the downstream channel. The relationship can be described by the following conditions:

When $\mathrm{H}(\mathrm{t}-1)+\mathrm{P}(\mathrm{t})-\mathrm{Kc} * \mathrm{ET} 0(\mathrm{t})-\mathrm{CN}>\mathrm{Hm}(\mathrm{t})$, Terraces do not require groundwater during this time, $\operatorname{Rg}(\mathrm{t})=0$

When $\mathrm{H}(\mathrm{t}-1)+\mathrm{P}(\mathrm{t})+\mathrm{W}_{\mathrm{G}}(\mathrm{t})-\mathrm{Kc}^{*} \mathrm{ETO}(\mathrm{t})-\mathrm{CN}>\quad \mathrm{Hm}(\mathrm{t})$, Terraced land use of part of groundwater $\mathrm{W}_{\mathrm{G}}(\mathrm{t})$, to keep terrace water level at $\mathrm{Hm}(\mathrm{t})$ At this time:

$$
\mathrm{Rg}(\mathrm{t})=\mathrm{Hm}(\mathrm{t})-\mathrm{H}(\mathrm{t}-1)-\mathrm{P}(\mathrm{t})+\mathrm{Kc} * \mathrm{ET}(\mathrm{t})+\mathrm{CN}
$$

When $\mathrm{H}(\mathrm{t}-1)+\mathrm{P}(\mathrm{t})+\mathrm{W}_{\mathrm{G}}(\mathrm{t})-\mathrm{Kc} * \mathrm{ET} 0(\mathrm{t})-\mathrm{CN}<\quad \mathrm{Hm}(\mathrm{t})$, Groundwater exposed during this period was fully used At this time, $\operatorname{Rg}(\mathrm{t})=\mathrm{W}_{\mathrm{G}}(\mathrm{t})$

When $\mathrm{H}(\mathrm{t}-1)+\mathrm{P}(\mathrm{t})+\mathrm{W}_{\mathrm{G}}(\mathrm{t})-\mathrm{Kc} *$ ET0 $(\mathrm{t})-\mathrm{CN}<\mathrm{Hn}(\mathrm{t}), \mathrm{Rg}(\mathrm{t})=$ $\mathrm{W}_{\mathrm{G}}(\mathrm{t})$, The amount of exposed groundwater $\mathrm{W}_{\mathrm{G}}(\mathrm{t})$ during this period was insufficient to meet the water requirements of the terraced crops, and the terraced fields encountered drought during this period.

$\mathrm{Hm}(\mathrm{t}) \longrightarrow$ The growth period of crops taken at $\mathrm{t}$ period is resistant to the depth of flooding $(\mathrm{mm})$

$\mathrm{Hn}(\mathrm{t}) \longrightarrow$ The drought-resistant depth of the crop during the period of $\mathrm{t}(\mathrm{mm})$

The above conditions describe the coupling relationship between outflow of groundwater reservoirs and irrigation and drainage of terraced irrigation. Among them, WG(t) has become a key factor in the supply and demand balance of terrace irrigation water. However, WG(t) depends on the recharge of groundwater reservoirs by rainfall and the regulation and excretion mechanisms of underground reservoirs themselves.

\subsection{Groundwater Reservoir Recharge and Nonlinear Regulation Mechanism}

The amount of groundwater reservoir replenishment is derived from the subsurface runoff generated by rainfall. It can be obtained by the basin hydrological model, but it requires a large amount of measured data to determine the model parameters. This study only has one year of actual measurement data, so the annual base flow coefficient is used to derive the infiltration recharge. the amount. According to Table 1, taking into account the difference in base flow coefficient between the vegetation area and the terrace area, the average base flow coefficient of the whole terrace area calculated based on the area weighted average is 0.295 . Then, the runoff depth Q0 $(\mathrm{mm})$ of replenishment of groundwater reservoirs by rainfall infiltration can be calculated as follows:

$$
\mathrm{Q}_{0}=0.295 * \mathrm{P}
$$

\section{$\mathrm{P}$-Rainfall (mm)}

According to "Watershed Hydrology Simulation Xin'anjiang Model and Shaanbei Model" (Zhao Renjun), according to the principle of linear reservoirs, the equation for the withdrawal of groundwater reservoirs can be expressed by the following formula:

$$
\mathrm{Q}_{\mathrm{t}}=\mathrm{Q}_{0} * \mathrm{e}^{-\mathrm{at}}
$$

The introduction of the discharge coefficient $\mathrm{K}$, combined with the water balance equation of the water withdrawal section $-\mathrm{Qdt}=\mathrm{dw}$, can be obtained by:

$$
\mathrm{Q}_{\mathrm{t}}=\mathrm{Q}_{0} * \mathrm{e}^{-\mathrm{t} / \mathrm{k}} \text { or } \mathrm{Q}_{\mathrm{t}+\Delta \mathrm{t}}=\mathrm{Q}_{\mathrm{t}} \mathrm{e}^{-\Delta^{\mathrm{t} / \mathrm{k}}}
$$

Take the time period $\Delta \mathrm{t}=1$ (days), $\mathrm{K}_{\mathrm{r}}=\mathrm{Q}_{\mathrm{t}+\Delta \mathrm{t}} / \mathrm{Q}_{\mathrm{t}}$

$\mathrm{K}_{\mathrm{r}}$ - The groundwater regression coefficient can be obtained from the withdrawal section of the underground runoff process line. In this paper, $\mathrm{Kr}=0.925$ is obtained from the groundwater process line divided by Stations A and B. There are:

$$
\mathrm{K}=-1 / \mathrm{L}_{\mathrm{n}} * \mathrm{~K}_{\mathrm{r}}
$$

According to the principle of water balance, the discharge of groundwater at any time is:

$$
W_{G}(t)=\Delta W_{G}=\int_{t}^{t+\Delta t} Q_{O} e^{-t / k} d t=W_{\mathrm{t}}\left(1-K_{r}\right)=W_{\mathrm{t}} \cdot K_{p}
$$

$\mathrm{Kp}=1-\mathrm{Kr}$, Outflow coefficient $\mathrm{Wt}$ — Total underground runoff during $\mathrm{t}$

Equation 7 simply considers the groundwater reservoir as a linear regulator and describes the process of rainfall infiltration recharging underground reservoirs and then flowing out to the surface. This description is based on the theory of "storing full production flow" and considers the groundwater storage space as a one-dimensional plane and a medium with even distribution of voids. However, in the underground reservoir of an isobaric site in the Ziyi area, the surface of the water is parallel to the slope of the terrain, and there is at least a $4.0 \mathrm{~m}$ "regulatory capacity" space, and the rainfall-infiltration recharge-excretion relationship is simply described by formula 7. Unsuitable, the impact of the regulation and storage of underground reservoirs on the discharge process should be considered. 


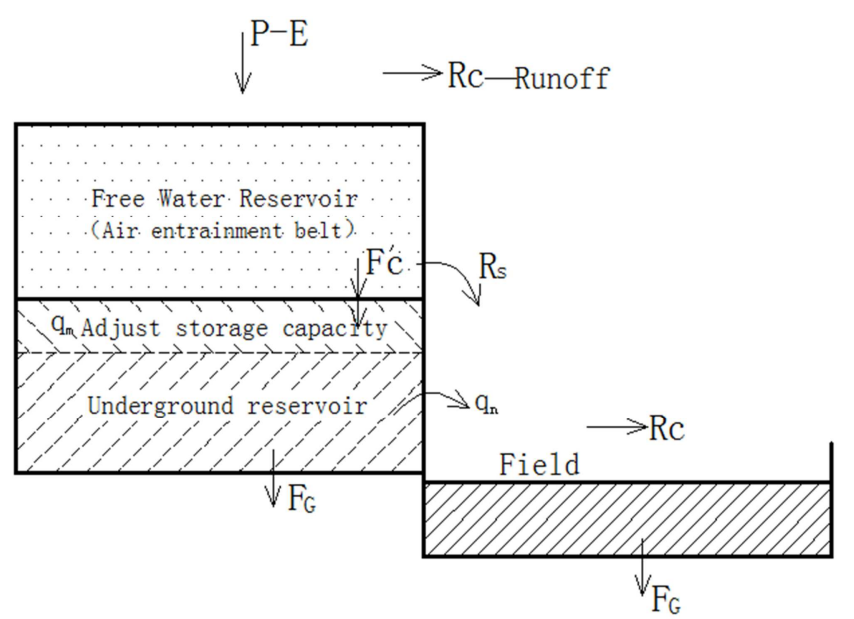

Figure 8. Schematic diagram of the principle of underground water storage.

Based on this, the introduction of underground reservoirs to adjust storage capacity qm, then the structure of underground water reservoirs is shown in Figure 8. According to the principle of full production and flow, after the amount of rainfall infiltration $\mathrm{Q} 0$ enters the vadose zone, a part of it $(\mathrm{Q} 0$ q0) is linearly adjusted by the vadose zone and excreted in the middle stream form (Rs)to become part of the WG, and the rest (set For q0) continue to infuse qm. Since the water level of the groundwater reservoir at constant slope level is always higher than the terrace field, under the action of gravity, as long as qm is not empty, it will "automatically" release the water quantity qn downstream at any time. Therefore, qn is the outflow process after the linear adjustment of the qm of the underground water reservoir. WG is composed of two parts:
Rs and qn. The flow of the two parts of the water source can be approximated by the principle of linear reservoir. We call it "bilinear autonomous regulation" and can be described by the following formula:

$$
\begin{gathered}
W_{G}(t)=\int_{t}^{t+\Delta t}\left(Q_{O}-q_{0}\right) e^{-t / k} d t+\int_{t}^{t+\Delta t} q_{m}(t) e^{-t / k} d t \\
\mathrm{q}_{m}(t)=q_{m}(t-1)+q_{0} \\
\mathrm{q}_{0}(t) \leq \mathrm{q}_{m}
\end{gathered}
$$

in the formula:q0(t) - Adjusted storage capacity after rainfall infiltration.

qm is the adjust the upper limit of storage capacity, The calculation can be expressed as the maximum amount of net irrigation water that can be provided by the adjusted storage capacity of the groundwater reservoir owned by each acre of terraces.

\subsection{Model Validation}

Equations 3 and 8 form the calculation model for the balance of the original gravity irrigation water cycle in ancient terraced fields. In order to test the correctness and practicality of the model, using the above-mentioned experimental observations to obtain the hydrogeological parameters, weather data, etc., using the formula 3 and formula 8 , the rice fields in the ancient terraces of the Ziyun Circle were calculated for 43 consecutive years from 1971 to 2013. Irrigation water supply and demand balance process, analysis of the ancient terraced area of the original ecological gravity

\begin{tabular}{|c|c|c|c|c|c|}
\hline parameter name & unit & Value & parameter name & unit & Value \\
\hline Runoff area (ecological vegetation area) & $\mathrm{km}^{2}$ & 55 & Groundwater flow coefficient & & 0.32 \\
\hline Production area (ancient terrace area) & $\mathrm{km}^{2}$ & 38 & Groundwater flow coefficient & & 0.26 \\
\hline Flat terrace area ratio & & 2.47 & Groundwater flow coefficient $\left(\mathrm{K}_{\mathrm{p}}\right)$ & & 0.075 \\
\hline
\end{tabular}
irrigation irrigation guarantee rate.

Table 4. Parameter Table (Hydrogeological Parameters) for Simulation of Supply and Demand Balance of Gravity Irrigation Water in Ancient Terraces

\begin{tabular}{|c|c|c|c|c|c|c|c|c|}
\hline \multirow{3}{*}{ Crop name } & \multicolumn{8}{|c|}{ Fertility stage } \\
\hline & \multicolumn{2}{|c|}{ Turn green (8days) } & \multicolumn{2}{|c|}{ Before childbirth (10 days) } & \multicolumn{2}{|c|}{ After childbirth (16 days) } & \multicolumn{2}{|c|}{ Field drying (7 days) } \\
\hline & $\mathbf{H}_{\mathrm{n}}$ & $\mathbf{H}_{\mathrm{m}}$ & $\mathbf{H}_{\mathrm{n}}$ & $\mathbf{H}_{\mathrm{m}}$ & $\mathbf{H}_{\mathrm{n}}$ & $\mathbf{H}_{\mathrm{m}}$ & $\mathbf{H}_{\mathrm{n}}$ & $\mathbf{H}_{\mathrm{m}}$ \\
\hline \multirow{4}{*}{ Medium rice } & 30 & 100 & 0 & 150 & -10 & 150 & -20 & 0 \\
\hline & \multicolumn{2}{|c|}{ Jointing booting (10 days) } & \multicolumn{2}{|c|}{ Heading (13 days) } & \multicolumn{2}{|c|}{ milk ripeness (18 days) } & \multicolumn{2}{|c|}{ yellow ripe (12 days) } \\
\hline & $\mathrm{H}_{\mathrm{n}}$ & $\mathrm{H}_{\mathrm{m}}$ & $\mathrm{H}_{\mathrm{n}}$ & $\mathrm{H}_{\mathrm{m}}$ & $\mathrm{H}_{\mathrm{n}}$ & $\mathrm{H}_{\mathrm{m}}$ & $\mathrm{H}_{\mathrm{n}}$ & $\mathrm{H}_{\mathrm{m}}$ \\
\hline & 0 & 180 & 0 & 180 & -5 & 120 & -10 & 60 \\
\hline
\end{tabular}

Table 5. Parameter Table for Simulating the Supply and Demand Balance of Gravity Irrigation Water in Ancient Terraces (Irrigation System Control Parameters).

The results of simulation calculations show that during the 43 consecutive years from 1971 to 2013, only short-term water shortages occurred from late August to early September in 2003 and 2013. In the latter part of August 2003, there was a continuous lack of water for 7 days and in the first half of
September, there was a lack of water for 6 days. There is a lack of water for 8 days in late August 2013. Based on 43 years of calculation, the guarantee rate of the original ecological gravity irrigation in ancient terraced mountains is $95 \%$. 
Table 6. Summary of Simulation Calculation Results of Irrigation Water Supply and Demand Balance Based on Underground Irrigation Water in Ancient Terraces.

\begin{tabular}{|c|c|c|c|c|c|c|c|}
\hline \multirow{2}{*}{$\begin{array}{l}\text { Year/ } \\
\text { month }\end{array}$} & \multicolumn{5}{|c|}{ Water supply for irrigation $\left(\mathrm{m}^{3} / \mathrm{mu}\right)$} & \multirow{2}{*}{ Water shortage month } & \multirow{2}{*}{ Water shortage days } \\
\hline & 6 & 7 & 8 & 9 & total & & \\
\hline 1971 & 56.6 & 53.9 & 50.2 & 33.9 & 194.7 & 0 & 0 \\
\hline 1972 & 50.2 & 33.7 & 76.9 & 22.2 & 183 & 0 & 0 \\
\hline$\ldots$ & $\ldots$ & $\ldots$ & $\ldots$ & $\ldots$ & $\ldots$ & & \\
\hline 2003 & 65.2 & 53.5 & 69 & 20.8 & 208.4 & 8,9 & 13 \\
\hline$\ldots$ & $\ldots$ & $\ldots$ & $\ldots$ & $\ldots$ & $\ldots$ & 0 & 0 \\
\hline 2013 & 32.5 & 73.4 & 83 & 0 & 188.9 & 8 & 8 \\
\hline
\end{tabular}

The above simulation results are highly consistent with the drought statistics in Hunan Province and Xinhua County. According to the Statistical Yearbook of Xinhua County, 2003 was a particularly severe drought since the liberation of Xinhua County.

Table 7. Statistics of drought-affected areas in Xinhua County over the years.

\begin{tabular}{|c|c|c|c|c|c|c|c|c|c|c|c|}
\hline years & 2000 & 2001 & 2002 & 2003 & 2004 & 2005 & 2006 & 2007 & 2008 & 2009 & 2010 \\
\hline Drought disaster area (million mu) & 1.4 & 2 & 12.3 & 36 & 0.2 & 1.6 & 1.28 & 4.86 & 1.28 & & 3.5 \\
\hline
\end{tabular}

In general years, the area due to drought disasters ranges from 0.2 to $48,000 \mathrm{mu}$. In 2003, the drought-damaged area was as high as $360,000 \mathrm{mu}$, which accounted for more than $40 \%$ of the cultivated area in Xinhua County. In this year, 89 counties and cities in Hunan province reached the drought standard, accounting for $93 \%$. The area affected by drought was $1,754,700$ hectares, which was rated as a particularly dry year.

In 2013, it was also a particularly arid year for a large area of Hunan Province. The drought-damaged area of Xinhua County was $420,000 \mathrm{mu}$. However, compared to the disaster conditions in Xinhua County and Hunan Province, the terraces in the clams of the Weifang Mountains were only short-lived for a few days.

\section{Conclusion}

Based on hydrological, meteorological, and geological explorations and other experimental observations of the isotropy groundwater reservoir and its bilinear self-regulating principles, this study clarified the sources, storage, and migration transformation methods of irrigation water sources in the terraces of the climatic and vertiginous fields. The coupling relationship between recharge, storage and drainage of this groundwater reservoir and irrigation and drainage of terraced fields has profoundly revealed the original ecological gravity irrigation mechanism of mountain terraces.

\section{Fund Project}

Funding for the Special Fund for Scientific Research in the Public Welfare Sector of the Ministry of Water Resources (201101030).

\section{References}

[1] Xu Zhifang, Nie Fangrong et al. Hunan Ziyijie terraced gravity irrigation system $[\mathrm{J}]$. China Rural Water and Hydropower, 2006(4): 73 74.

[2] Zhao Renjun. Watershed hydrological simulation - Xinanjiang model and northern Shaanxi model. China Water Resources Press. 1984.

[3] Qin Renqiu. An analysis of the water retention mechanism of the terraces in the crimson field [J]. Hunan Water Resources and Hydropower, 2005(3):47 48.

[4] Li Guiyuan et al. Based on Digital Filtering Method for Analysis of Water Source Structure of Terraced Fields in the Purple-Column Sector [J]. Anhui Agricultural Science and Technology, 2012, 40(18): 9956-9757.

[5] Xiao Menghua, Yu Shuang'en, Zhang Yunlong. Changes of nitrogen concentration for surface and groundwater in flooding paddy field under controlled drainage [J]. Transactions of the Chinese Society of Agricultural Engineering, 2011, 27(10):180-186.

[6] Qiao Xin, Shao Dongguo, liu Huanhuan, et al. Study on the moving and transforming law of $\mathrm{N}$ and $\mathrm{P}$ under water-saving irrigation and controlled drainage[J]. Journal of Hydraulic Engineering, 2011, 42(7):862-868.

[7] Yu shuang'en, Miao Zimei, Xing Wengang, et al. Research advance on irrigation-drainage for rice by using field water level as regulation index [J]. Journal of Irrigation and Drainage, 2010, 29(2): 134-136.

[8] Guo xiangping, yuan jing, guo feng, et al. Preliminary study on water-catching and controlled irrigation technology of rice $[\mathrm{J}]$. Transactions of the Chinese Society of Agricultural Engineering, 2009, 25(4):70-73.

[9] Liu zhongpei, yu furong, jiao jianwei. Impact identification of planting scale and precipitation variation on agricultural groundwater exploitation [J]. Advance in Water Science, 2012, 27(2):240-245. 
[10] Yanming river, wang jinzhe, zhang guanghui, et al. Influence of precipitation during crops growing and groundwater yield for agriculture on groundwater dynamic

[11] Cheng Jichengs, Jiang meiqiu. Vally geomorphologie mathematical model [M]. Beijing:Science Press, 1986:1-8.

[12] Sun Chongliang, Wang Juanle. The progress on automatic basin streamline extracting \& classifying methods based on $\operatorname{DEM}\{J\}$. Progress in Geography, 2008, 27(1):118-124.

[13] Lin X Y, Liao Z S, Qian Y P, et al. Baseflow separation for groundwater study in the Yellow River basin, China [J]. Journal of Jilin University (Earth Science Edition), 2009, 39(6):959-967.

[14] Li W S, FENG L, SUN S L, et al. Influence of Zaling and Eling Lake on the annual discharge of the Huanghe River Source Area [J]. Acta Geographica Sinica, 2001, 56(1):75-82.

[15] Xiong LIhua, Guodongsheng, KIERAN M O. Review of methods for deriving physical descriptors of thr watershed topography from [J]. Advances in Water Science, 2002, 13(6):775-780.

[16] Li Guiyuan, Li Kangyong, Hu chunyan. Research on optimization of field irrigation and drainage management of super hybrid rice in south china [J]. China Rural Water and Hydropower, 2018(5):14-17.

[17] a. satyanarayana, $\mathrm{T} \mathrm{m}$ thiyagarajan. Utilizing rainfall and alternate wetting and drying irrigation for high water productivity in irrigated-lowland paddy rice in southern Taiwan. [J] Plant Production Science, 2017, 20(1):24-35

[18] A. satyanarayana, $\mathrm{T} \mathrm{m}$ thiyagarajan. Oppprtunities for water saving with higher yield from the system of rice intensification. [J] Irigation Science, 2007, 25(2):99-115.

[19] Jaffar Basha S, A Sitha Rama Sarma. Yield and water use efficiency of rice relative to scheduling of irrigation. [J]. Annals of Plant Sciences, 2017, 6(02):1559-1565

[20] Zhuang Yang, lu jian, jiao xi yun. Influence of groundwater depth on cotton irrigation system. [J]. water saving irrigation, 2015, $15(3): 15-18$

\section{Biography}

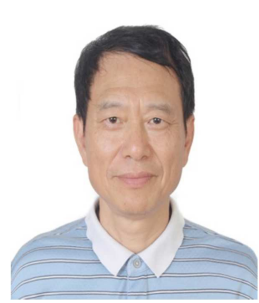

Li Guiyuan (1963-), male, Hengnan County of Hunan Province, Professor, Engaged in research, development and utilization of water resources and management. 